\title{
Support Vector Regression and Genetic Algorithm for HVAC Optimal Operation
}

\author{
Ching-Wei Chen and Yung-Chung Chang \\ Department of Energy and Refrigerating Air-Conditioning Engineering, National Taipei University of Technology, No. 1, Sec. 3, \\ Chung-Hsiao E. Road, Taipei 10608, Taiwan \\ Correspondence should be addressed to Ching-Wei Chen; jason.weil838@gmail.com
}

Received 11 October 2015; Revised 18 February 2016; Accepted 30 March 2016

Academic Editor: Marco Mussetta

Copyright (C) 2016 C.-W. Chen and Y.-C. Chang. This is an open access article distributed under the Creative Commons Attribution License, which permits unrestricted use, distribution, and reproduction in any medium, provided the original work is properly cited.

This study covers records of various parameters affecting the power consumption of air-conditioning systems. Using the Support Vector Machine (SVM), the chiller power consumption model, secondary chilled water pump power consumption model, air handling unit fan power consumption model, and air handling unit load model were established. In addition, it was found that $R^{2}$ of the models all reached 0.998 , and the training time was far shorter than that of the neural network. Through genetic programming, a combination of operating parameters with the least power consumption of air conditioning operation was searched. Moreover, the air handling unit load in line with the air conditioning cooling load was predicted. The experimental results show that for the combination of operating parameters with the least power consumption in line with the cooling load obtained through genetic algorithm search, the power consumption of the air conditioning systems under said combination of operating parameters was reduced by $22 \%$ compared to the fixed operating parameters, thus indicating significant energy efficiency.

\section{Introduction}

Conventional chillers require the highest power consumption among components of air conditioning systems. In recent years, with the availability of numerous studies on chiller efficiency, chillers have continued to become more energy efficient [1-3]; relatively, the power consumption ratios of pumps and fans have become higher. In addition, central air conditioning system control involves greater complexity, as a centralized air conditioning system comes with many ancillary parts. Therefore, the operating efficiency of pumps and fans has particular importance. The main subject of discussion in this paper is how to achieve optimized control of water and air loop load changes through gear control. Through the thermal load balance equation of the air handling unit, the relationship between the load and relevant variables was established [4]. In this equation, the variables include the operating parameters of chiller, pump, and air handling unit. In other words, optimized operation of these three types of equipment can be simultaneously taken into consideration. Through the powerful search capacity of genetic algorithm [5-7], the optimized combination of outlet temperature of chilled water, the air flow of air handling unit, and secondary chilled water flow was searched simultaneously to obtain the least power consumption for cooling load.

Schwedler and Bradley [8] proposed the correlations among chiller power consumption, air conditioning load, condenser, and outlet temperature of chilled water when the operating characteristics of each chiller vary. The average loading method was adopted to control and solve the optimized load distribution and chilled water temperature setting point of the chiller [9-11]. Through chilled water flow control, the water saving effect can be enhanced. Lu et al. [12] put forth a comprehensive optimized control method, where the influential relationships among all controllable variables and objective functions in the system were expressed using mathematical equations and the best control setting point among them was found. Ding and Xianzhong [13] suggested using linear regression to establish a load prediction model. On the other hand, Yao et al. [14] mentioned the use of the RBF neural network to establish a prediction model. Chang et al. [15] proposed using the cubic polynomial equation to express the performance curve of the chiller and using the gradient method to engage in chiller load 


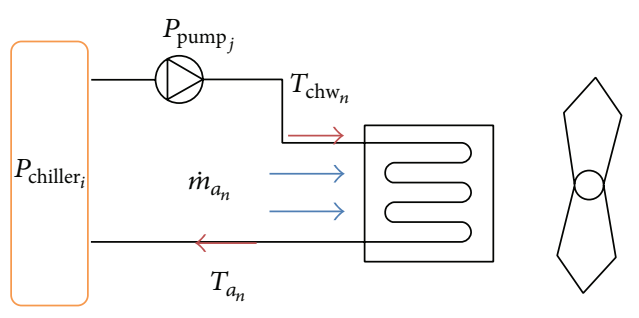

FIGURE 1: Illustration of the basic configuration of an air handling unit together with a chiller and water pump.

distribution optimization in order to obtain the least total power consumption. Beghi et al. [16] used the multiobjective genetic algorithm to propose ways to manage energy saving of multiple sets of chiller systems.

In this paper, the chiller, chilled water pump loop, and air handling unit air loop were integrated and controlled. Then, the air handling unit thermal balance equation was adopted to serve as a reference for setting outlet temperature of chilled water, air flow, and chilled water flow. The power consumption model established through the neural network and SVM replaced the model established through linear regression [17-20]. Finally, genetic algorithm was conjunctively used to search the optimized setting values of the three variables in order to obtain the least power consumption of the equipment under the various load conditions.

\section{System Structure}

Figure 1 illustrates the basic configuration of an air handling unit. The air handling unit can be divided into air loop and chilled water loop. The principle of cycling involves transmitting the indoor cooling load to the chilled water. Then, through the chilled water pump, the chilled water that has undergone thermal exchange is sent back to the chiller to complete one cycle. Based on the thermal balance equation of the air handling unit, we can express the air handling unit load equation as [21]

$$
Q=\frac{d_{1} \dot{m}_{a_{n}}^{e}}{1+d_{2}\left(\dot{m}_{a_{n}} / \dot{m}_{\mathrm{chw}_{n}}\right)^{e}}\left(T_{a_{n}}-T_{\mathrm{chw}_{n}}\right)
$$

The empirical parameters, $d_{1}, d_{2}$, and $e$, need to be identified from experiment data.

The chiller power consumption, through the multiple regression [22], can be expressed as the following equation:

$$
\begin{aligned}
P_{\text {chiller }_{i}}= & k_{0}+k_{1, i}\left(T_{\text {cwr }_{i}}-T_{\text {chws }_{i}}\right) \\
& +k_{2_{i}}\left(T_{\text {cwr }_{i}}-T_{\text {chws }_{i}}\right)^{2}+k_{3_{i}} Q_{\text {chiller }_{i}} \\
& +k_{4_{i}} Q_{\text {chiller }_{i}}{ }^{2}+k_{5_{i}}\left(T_{\text {cwr }_{i}}-T_{\text {chws }_{i}}\right) Q_{\text {chiller }_{i}} .
\end{aligned}
$$

The air handling unit fan power consumption and the pump power consumption have a cubic relationship with air handling unit air flow and chilled water flow [23], which can be expressed as the following equations through multiple regression:

$$
\begin{aligned}
P_{\mathrm{fan}_{n}} & =k_{0}^{\prime}+k_{1}^{\prime} \dot{m}_{a_{n}}+k_{2}^{\prime} \dot{m}_{a_{n}}{ }^{2}+k_{2}^{\prime} \dot{m}_{a_{n}}{ }^{3}, \\
P_{\text {pump }_{j}} & =k_{0}^{\prime \prime}+k_{1}^{\prime \prime} \dot{m}_{\mathrm{chw}_{n}}+k_{2}^{\prime \prime} \dot{m}_{\mathrm{chw}_{n}}{ }^{2}+k_{3}^{\prime \prime} \dot{m}_{\mathrm{chw}_{n}}{ }^{3} .
\end{aligned}
$$

The empirical parameters, $k_{0} \sim k_{5 i}, k_{0}^{\prime} \sim k_{2}^{\prime}$, and $k_{0}^{\prime \prime} \sim k_{3}^{\prime \prime}$, are acquired from regression analysis.

The three operating parameters of the air conditioning system: outlet temperature of chilled water of chiller $\left(T_{\text {chw }}\right)$, secondary chilled water flow $\left(\dot{m}_{\text {chw }}\right)$, and air handling unit air flow $\left(\dot{m}_{a}\right)$ affect the power consumption of the chiller $\left(P_{\text {chiller }}\right)$, secondary water pump power consumption $\left(P_{\text {pump }}\right)$, and air handling unit power consumption $\left(P_{\text {fan }}\right)$. When the same load is provided by the air conditioning system, the three operating parameters will have multiple combinations. The methodology is shown in Figure 2.

\section{Support Vector Machine (SVM) and Support Vector Regression (SVR)}

Although many methods have been used to predict the power consumption models of chillers [24], the SVM, compared to the neural network, is a relatively newer artificial intelligence classification method. Through the correlational relationships of the independent variables and dependent variables, low-dimensional vector spaces are projected to high-dimensional vector spaces. Unlike the neural network, there is no need to carry out the massive calculations of the hidden layers during model training, thus greatly reducing training time. The disadvantage of excessive learning can also be prevented in nonlinear data classification. In terms of classification, the SVM can be divided into linear SVM and nonlinear SVM $[25,26]$. In this study, we use nonlinear SVM to do regression.

3.1. Support Vector Machine (SVM). In Figure 3 suppose that we have some separating hyperplane to separate data, and we have two support hyperplanes, where $w$ is the normal vector to the hyperplane. Let $d_{+}, d_{-}$be the shortest distance from the separating hyperplane to support hyperplane. Define the "margin" of a separating hyperplane to be $d_{+}, d_{-}$[27].

In the case of "linear separable," the hyperplane in existence can divide the input space. The separating hyperplane in this area can be expressed as $w^{T} x+b=0$; the hyperplane solution can be regarded as a quadratic programming solution, as the following equation:

$$
\begin{array}{ll}
\text { Minimize } & \phi(w)=\frac{1}{2} w^{T} w \\
\text { Subject to } & y_{i}\left(w^{T} x_{i}+b\right) \geq 1, \quad i=1,2, \ldots, n
\end{array}
$$




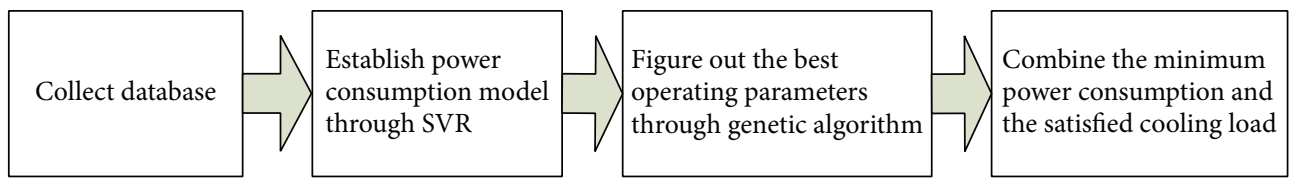

FIGURE 2: The flowchart of this study methodology in optimized operation of chilled water system.

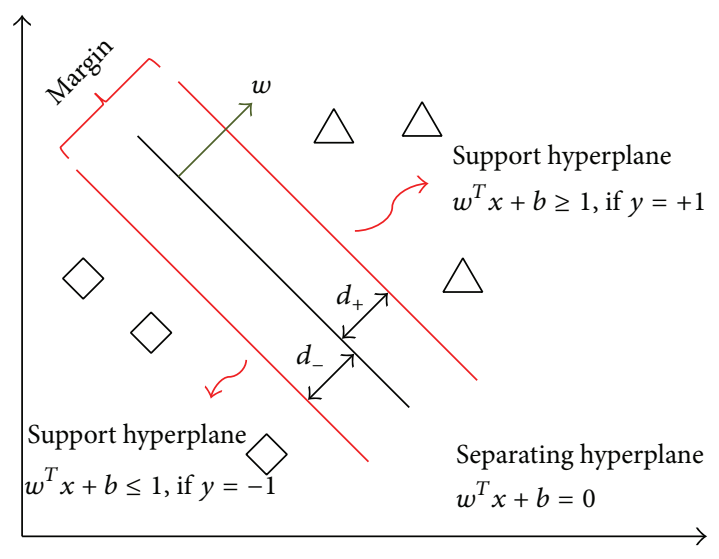

FIgURE 3: The hyperplane and margin.

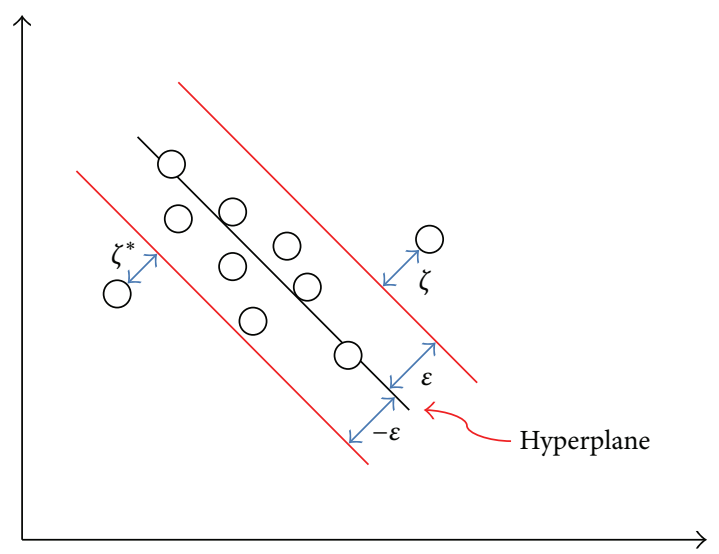

FIGURE 4: The feature space of SVR.

This condition is called the primal problem; when we through the Lagrange [28], the multiplier can be rewritten as the following equation:

$$
\begin{aligned}
\text { Minimize } & L_{p}(w, b, \alpha) \\
& =\frac{1}{2}\left\|w^{2}\right\|-\sum_{i=1}^{n} \alpha_{i}\left[y_{i}\left(w^{T} x_{i}+b\right)-1\right]
\end{aligned}
$$

Subject to $\alpha_{i} \geq 0, \quad i=1,2, \ldots, n$.

That can be efficiently solved by quadratic programming algorithms and then through KKT (Karush-Kuhn-Tucker) conditions [29], the equation can be converted as

$$
d(x)=x \cdot w^{*}+b^{*}=\sum_{i=1}^{n} y_{i} \alpha_{i}\left(x \cdot x_{i}\right)+b^{*} .
$$

3.2. Support Vector Regression (SVR). SVR is SVM regression through a new type of loss function called $\varepsilon$-insensitive loss function. And it can be described by introducing (nonnegative) slack variables $\xi, \xi^{*}$ to measure the deviation of training samples outside $\varepsilon$-insensitive zone. Figure 4 shows the data map to the high-dimensional feature space [30,31].

Thus SVR is formulated as minimization of the following function:

$$
\begin{aligned}
& \text { Minimize } \phi\left(w, \zeta, \xi^{*}\right)=\frac{1}{2} w^{T} w+C\left(\sum_{i=1}^{n} \zeta_{i}+\zeta_{i}^{*}\right) \\
& \text { Subject to } y_{i}-w^{T} f\left(x_{i}\right)-b \leq \varepsilon+\zeta_{i}{ }^{*} \text {, } \\
& i=1,2, \ldots, n \\
& -y_{i}+w^{T} f\left(x_{i}\right)+b \geq \varepsilon+\zeta_{i}, \\
& i=1,2, \ldots, n \\
& \xi_{i}, \xi_{i}^{*} \geq 0 .
\end{aligned}
$$

The parameter $C$ is a penalty factor to control the degree of punishment of samples beyond the error $\varepsilon$. Training errors above $\varepsilon$ are denoted by $\xi_{i}^{*}$ whereas training errors below $\varepsilon$ are denoted by $\xi_{i}$.

Through the Lagrange and KKT, the regression function is shown as the below function:

$$
f(x)=\sum_{i=1}^{n}\left(\alpha_{i}+\alpha^{*}{ }_{i}\right) k\left(x, x_{i}\right)+b^{*},
$$

where $k\left(x, x_{i}\right)=\varphi(x) \cdot \varphi\left(x_{i}\right)$ is kernel function. Common core functions are as shown as follows:

Linear kernel is

$$
x_{i} * y_{i}
$$

Polynomial kernel is

$$
\left(\operatorname{gamma} * x_{i} * y_{i}+\text { coef } 0\right)^{\text {degree }} .
$$

Radiation basis function kernel is

$$
\exp \left(-\operatorname{gamma} *\left|x_{i}-y_{i}\right|^{2}\right) \text {. }
$$

After SVR training, the power consumption for chiller, air handling unit, secondary chilled water pump, and air handling unit load models can be obtained, which can be used to obtain optimized operating parameters by genetic algorithm [32]. 


\section{Genetic Algorithm}

The genetic algorithm (GA) is developed by Holland [33] in his book in 1975. The genetic algorithm is based on Darwinian's theory of survival of the fittest to solve both constrained and unconstrained optimization problems. Genetic algorithm is analogous to those in the selection process that mimics biological evolution: selection, reproduction, crossover, and mutation. The main advantage of the parallelism of GA is having multiple points in search space so that the problem of local maximum generally does not exist [34].

4.1. Initial Population. In order to find the best load distribution, a highly accurate prediction model should be first established to find the objective function of the least power consumption, as shown in the following equation:

$$
\mathrm{kW}_{\text {total }}=\operatorname{Min}\left(\sum_{i=1}^{I} P_{\text {chiller }_{i}}+\sum_{n=1}^{N} P_{\text {fan } n}+\sum_{j=1}^{J} P_{\text {pump }_{j}}\right) .
$$

The variables of the objective functions are randomly selected, as shown in the following equations, to generate the initial population made up of 900 sets of solutions:

$$
\begin{aligned}
T_{\mathrm{chws}_{i}}= & \left(T_{\mathrm{chws}_{i, \max }}-T_{\mathrm{chws}_{i}, \mathrm{~min}}\right) \times \operatorname{random}(0,1) \\
& +T_{\mathrm{chws}_{i}, \min }, \\
\dot{m}_{a_{n}}= & \left(\dot{m}_{a_{n}, \max }-\dot{m}_{a_{n}, \min }\right) \times \operatorname{random}(0,1) \\
& +\dot{m}_{a_{n}, \min }, \\
\dot{m}_{\mathrm{chw}_{j}}= & \left(\dot{m}_{\mathrm{chw}_{j}, \max }-\dot{m}_{\mathrm{chw}_{j}, \min }\right) \times \operatorname{random}(0,1) \\
& +\dot{m}_{\mathrm{chw}_{j}, \min } .
\end{aligned}
$$

The error between the predicted air conditioning cooling load and the actual air conditioning cooling load serves as the raw fitness, as shown in the following equation:

$$
F(i, t)=\sum_{j=1}^{N}\left|Q(i, j)-Q_{\text {real }}(j)\right|
$$

where $F(i, t)$ is raw fitness of generation $t$ in individual $i$; $Q(i, j)$ is load prediction value inputted at $j$ in individual; and $Q_{\text {real }}(j)$ is actual air conditioning load at $j$.

The smaller the fitness is, the closer the prediction value is to the actual value.

As shown in the flowchart in Figure 5, under the conditions of the known cooling load $\left(Q_{\text {Load }}\right)$, return air wet bulb temperature $\left(T_{a}\right)$, and inlet temperature of cooling water $\left(T_{\mathrm{cwr}}\right)$, three operating parameters were randomly produced: the outlet temperature of chilled water in the chiller $\left(T_{\text {chws }}\right)$, secondary chilled water flow $\left(\dot{m}_{\mathrm{chw}}\right)$, and air handling unit air flow $\left(\dot{m}_{a}\right)$. Then, the equipment power consumption models were substituted into the equation to obtain the power consumption $\left(P_{\text {chiller }}\right)$, secondary water pump power consumption $\left(P_{\text {pump }}\right)$, and air handling unit fan power consumption $\left(P_{\text {fan }}\right)$. After computing fitness, those nearest to the cooling load and with the least power consumption in the population were arranged in sequence to retain the moderately superior ones for reproducing a next population and execute mating and mutation for inferior ones. After 500 times of iteration, we can get the least power consumption and the cooling load is satisfied. Consider the following:

$$
\begin{aligned}
& P_{r}: \text { the reproduction process, } \\
& P_{c}: \text { the crossover process, } \\
& P_{m}: \text { the mutation process. }
\end{aligned}
$$

4.2. Reproduction. Through the ranking approach, the 900 individuals in this paper were ranked according to fitness. Those with the best fitness (i.e., the top $1 \%$ of the smallest fitness) were used as targets for copying.

4.3. Crossover. Since it takes two to mate, after eliminating the top $1 \%$, the remaining $98 \%$ were used as the length of mating. The chiller power consumption or the air handling unit power consumption at the functional end was randomly selected and mated to enter the next population and carry out fitness ranking.

4.4. Mutation. Unlike mating, it takes only one to mutate, as it is a type of asexual reproduction. For the remaining $1 \%$ of the population, the chiller power consumption or the air handling unit power consumption was randomly selected. Through the outlet temperature of chilled water and air handling unit air flow, mutation was calculated before finally entering the next population and carrying out fitness ranking.

The calculation ends when the population reaches 500 through copying, mating, and mutation. In Figure 6, the calculation has been converged. From the subpopulation obtained, the best fitness solution will be the best solution sought.

\section{Results and Discussion}

This experimental system is primary-secondary central air conditioning system with a fixed-frequency scroll compressor. When the preset outlet temperature of chilled water is reached, the on/off control and hot gas bypass methods are used in loading and unloading. The model establishment data comes from the air conditioning experimental system actually operated for three months from 2009/4/17 to 2009/6/11. The outlet and inlet temperature of chilled water in the chiller, the outlet and inlet temperature of chilled water in the air handling unit, the outlet and inlet temperature of cooling water, chilled water flow, return air wet bulb temperature, chiller power consumption, pump power consumption, air handling unit power consumption, and other related data were compiled to calculate the actual load of the air handling unit.

For three days from $2009 / 6 / 14$ to $2009 / 6 / 16$, the data collected at partial loading rates of $0.3 \sim 0.5,0.75 \sim 1$, and $0.5 \sim$ 0.75 were used to crossmatch predicted air conditioning load and power consumption. The experiment was crossmatched 


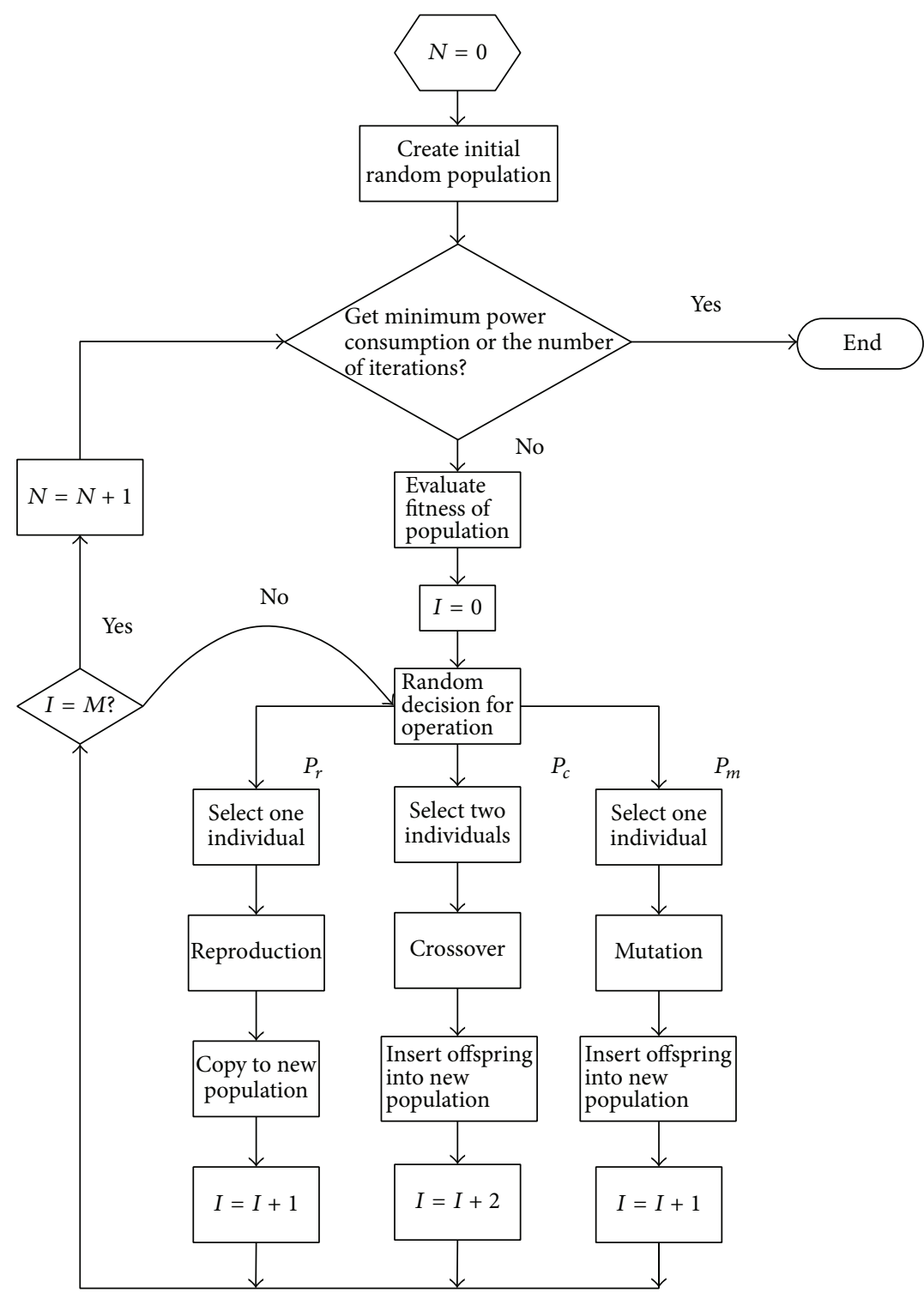

FIGURE 5: The flowchart of genetic algorithm applied in optimized operation of chilled water system.

with the air conditioning system at fixed outlet temperature of chilled water, fixed air handling unit air flow, and fixed secondary flow model (hereinafter referred to as fixed operating parameter model) from 9:00 a.m. in the morning to 6:00 p.m. in the evening to record the operating parameters. Then the data taken every 20 minutes on average were compiled. As shown in Table 1, there are a total of 81 operating parameter conditions. The 3-day operation data serves as the base data for comparison. In addition, based on the base data, the outlet temperature of chilled water, air handling unit air flow, and secondary chilled water flow operation model (hereinafter referred to as optimized operating parameter model) were compared.

Under the 81 known conditions (inlet temperature of cooling water, return air wet bulb temperature, and air

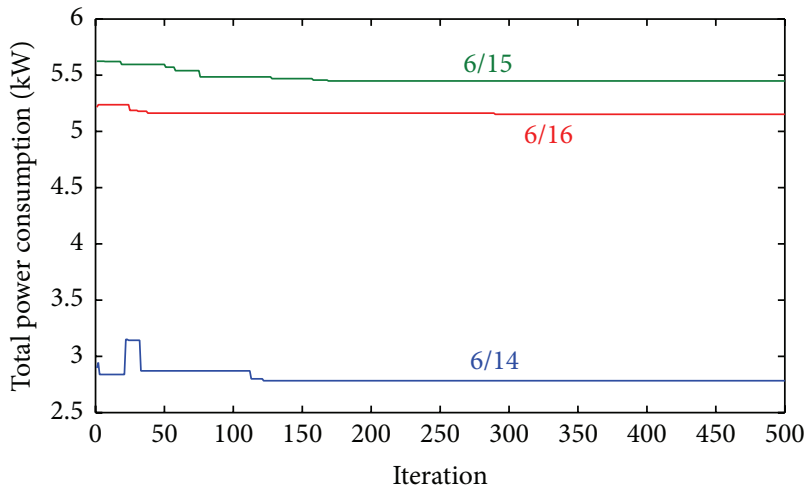

FIgURE 6: The convergence diagram of six segments of data for model establishment. 
TABLE 1: Operating parameters.

\begin{tabular}{|c|c|c|c|c|c|}
\hline Day & Time & $\begin{array}{l}\text { Wet bulb temperature } \\
{ }^{\circ} \mathrm{C}\end{array}$ & $\begin{array}{l}\text { Inlet temperature of cooling water } \\
{ }^{\circ} \mathrm{C}\end{array}$ & $\begin{array}{c}\text { Load } \\
\text { RT }\end{array}$ & $\begin{array}{l}\text { Initial total power consumption } \\
\mathrm{kW}\end{array}$ \\
\hline $2009 / 6 / 14$ & $9: 20$ & 22.23 & 27.20 & 2.48 & 3.71 \\
\hline $2009 / 6 / 14$ & $9: 40$ & 18.94 & 27.62 & 2.49 & 3.74 \\
\hline $2009 / 6 / 14$ & $10: 00$ & 18.12 & 27.62 & 2.51 & 3.74 \\
\hline $2009 / 6 / 14$ & $10: 20$ & 17.59 & 27.57 & 2.48 & 3.76 \\
\hline $2009 / 6 / 14$ & $10: 40$ & 19.02 & 27.34 & 2.65 & 3.67 \\
\hline$\vdots$ & $\vdots$ & $\vdots$ & $\vdots$ & $\vdots$ & $\vdots$ \\
\hline $2009 / 6 / 14$ & $16: 20$ & 19.48 & 24.82 & 2.18 & 3.47 \\
\hline $2009 / 6 / 14$ & $16: 40$ & 19.47 & 24.77 & 2.15 & 3.46 \\
\hline $2009 / 6 / 14$ & $17: 00$ & 19.26 & 24.77 & 2.06 & 3.44 \\
\hline $2009 / 6 / 14$ & $17: 20$ & 19.20 & 24.85 & 2.07 & 3.46 \\
\hline $2009 / 6 / 14$ & $17: 40$ & 19.25 & 24.99 & 2.10 & 3.46 \\
\hline $2009 / 6 / 14$ & 18:00 & 19.29 & 25.08 & 2.11 & 3.46 \\
\hline $2009 / 6 / 15$ & $9: 20$ & 21.88 & 26.80 & 2.37 & 3.54 \\
\hline $2009 / 6 / 15$ & $9: 40$ & 17.48 & 28.12 & 4.27 & 6.07 \\
\hline $2009 / 6 / 15$ & $10: 00$ & 16.89 & 28.20 & 4.10 & 6.03 \\
\hline $2009 / 6 / 15$ & $10: 20$ & 16.85 & 28.28 & 4.13 & 6.04 \\
\hline $2009 / 6 / 15$ & $10: 40$ & 16.84 & 28.46 & 4.17 & 6.06 \\
\hline$\vdots$ & $\vdots$ & $\vdots$ & $\vdots$ & $\vdots$ & $\vdots$ \\
\hline $2009 / 6 / 15$ & $16: 20$ & 17.04 & 28.21 & 4.03 & 5.99 \\
\hline $2009 / 6 / 15$ & $16: 40$ & 16.84 & 28.13 & 3.97 & 5.98 \\
\hline $2009 / 6 / 15$ & $17: 00$ & 16.89 & 28.07 & 3.94 & 5.97 \\
\hline $2009 / 6 / 15$ & $17: 20$ & 16.80 & 27.95 & 3.93 & 5.95 \\
\hline $2009 / 6 / 15$ & $17: 40$ & 16.77 & 27.97 & 3.92 & 5.94 \\
\hline $2009 / 6 / 15$ & $18: 00$ & 16.70 & 27.91 & 3.90 & 5.94 \\
\hline $2009 / 6 / 16$ & $9: 20$ & 21.91 & 26.89 & 2.65 & 3.57 \\
\hline $2009 / 6 / 16$ & $9: 40$ & 21.57 & 27.12 & 2.77 & 3.60 \\
\hline $2009 / 6 / 16$ & $10: 00$ & 20.97 & 27.38 & 2.73 & 3.62 \\
\hline $2009 / 6 / 16$ & $10: 20$ & 20.39 & 27.27 & 2.75 & 3.58 \\
\hline $2009 / 6 / 16$ & $10: 40$ & 20.90 & 27.66 & 2.77 & 3.61 \\
\hline$\vdots$ & $\vdots$ & $\vdots$ & $\vdots$ & $\vdots$ & $\vdots$ \\
\hline $2009 / 6 / 16$ & $16: 40$ & 19.56 & 27.52 & 2.68 & 3.55 \\
\hline $2009 / 6 / 16$ & $17: 00$ & 19.43 & 27.62 & 2.69 & 3.57 \\
\hline $2009 / 6 / 16$ & $17: 20$ & 19.53 & 27.71 & 2.68 & 3.60 \\
\hline $2009 / 6 / 16$ & $17: 40$ & 19.44 & 27.65 & 2.68 & 3.58 \\
\hline $2009 / 6 / 16$ & $18: 00$ & 19.48 & 27.59 & 2.70 & 3.59 \\
\hline $2009 / 6 / 16$ & $16: 40$ & 19.56 & 27.52 & 2.68 & 3.55 \\
\hline
\end{tabular}

conditioning cooling load), the best outlet temperatures of chilled water, secondary chilled water flow, and air handling unit air flow that are in line with the conditions with the least cooling load and power consumption were simultaneously searched. The convergence diagram is as shown in Figure 6. Under different partial loads during the 3-day operation, 500 times of iteration calculation all reached convergence. As shown in Figure 7, the chiller with the partial loading rates of $0.3 \sim 0.5$, through SVR prediction, showed the actual power consumption and simulated power consumption of
$R^{2}=0.999$. As shown in Figure 8 , the chiller with the partial loading rates of $0.5 \sim 1.0$, through SVR prediction, showed the actual power consumption and simulated power consumption of $R^{2}=0.998$. As shown in Figure 9, the relationship between the power consumption and flow of the chilled water pump, as predicted by SVR, showed the actual power consumption and simulated power consumption of $R^{2}=0.999$. As shown in Figure 10, the actual power consumption and simulated power consumption of the fan, as predicted by SVR, showed that $R^{2}=0.999$. As shown in 


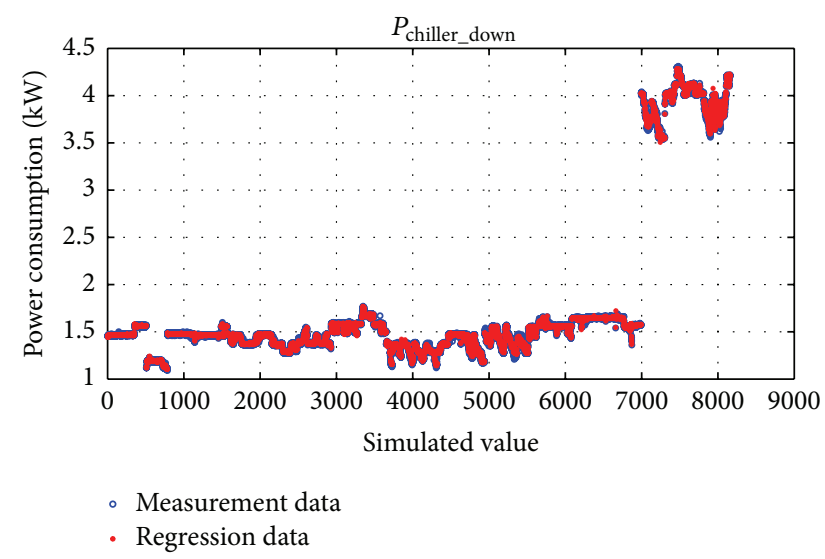

FIGURE 7: The actual power consumption and simulated chiller power consumption at low load.

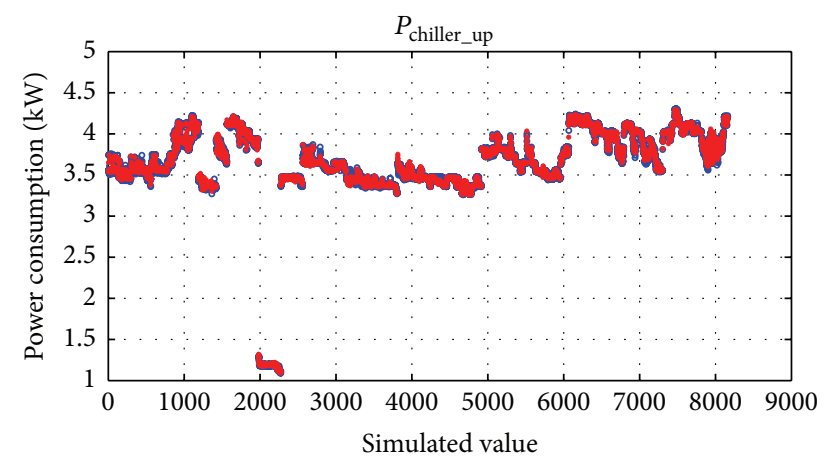

- Measurement data

- Regression data

FIGURE 8: Actual load and simulated load of chiller through SVR prediction.

Figure 11, the actual load and simulated load of air handling unit, as predicted by SVR, showed that $R^{2}=0.999$. Thus supporting SVM training time is far lower than that of the neural network, as shown in Table 2. The best operating result of power consumption is as shown in Figure 12. Under different partial loading rates during the 3-day operation, the total power consumption under the best operation was lower than the total power consumption under operation at fixed water temperature, thus indicating significant energy saving result. As shown in Figure 13, the 3-day total power consumption under the best operation and the operation at fixed water temperature was compared. On 6/14 under the condition of low partial loading rate operation, the energy reduction was $24.78 \mathrm{~kW}$; on $6 / 15$ under the condition of high partial loading rate, the energy reduction was $30.21 \mathrm{~kW}$; on $6 / 16$ under the condition of medium partial loading rate, $27.35 \mathrm{~kW}$ of energy was saved. Through genetic algorithm, the best operating settings for outlet temperature of chilled water, air handling unit air flow, and chilled water flow results are as shown in Table 3.

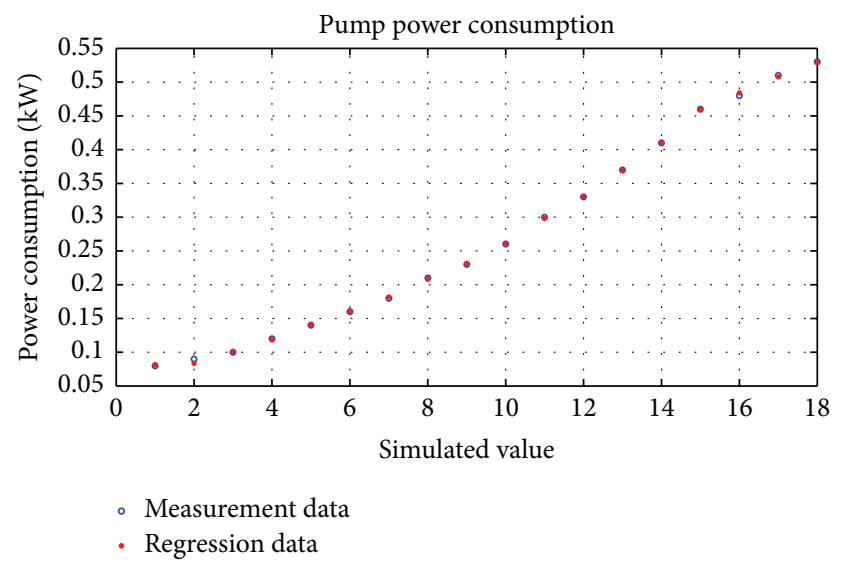

FIgUrE 9: Actual load and simulated load of pump through SVR prediction.

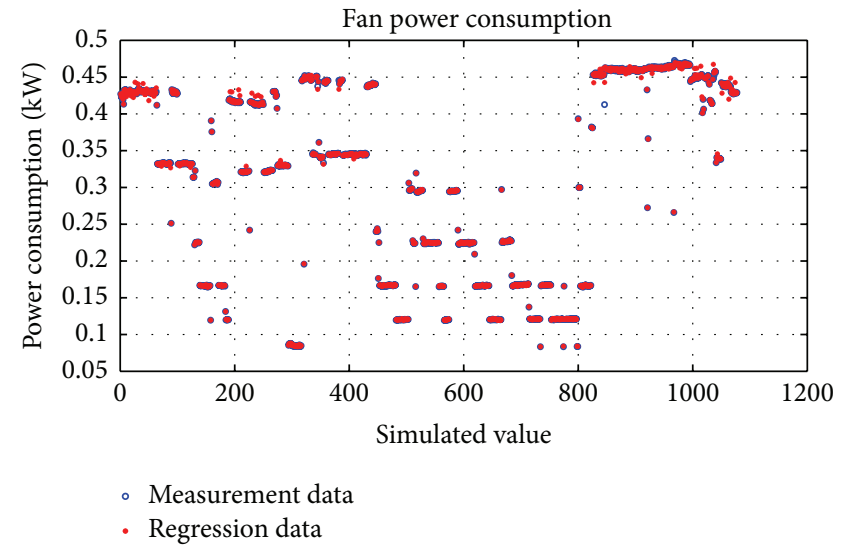

FIGURE 10: Actual load and simulated load of fan through SVR prediction.

\section{Conclusion}

The dependent variables contained in the air handling unit thermal balance equation used in this paper include chiller, air handling unit, and pump operating parameters. At the same time, optimized operation of these three types of equipment can also be taken into account. Through the powerful search capacity of genetic algorithm, the best combination of outlet temperature of chilled water, air handling unit air flow, and secondary chilled water flow is simultaneously searched. With satisfied loading, the total power consumption is also optimized. The $R^{2}$ values of the chiller power consumption model, air handling power consumption model, pump power consumption model, and air condition loading model established through the SVM all reached above 0.998 . They also possess high reliability when used to predict the power consumption and air condition load of individual components. In terms of training time, they are considered speedier and simpler compared to the neural network. Compared to the total power consumption when operated under fixed parameters, operating parameters 
TABLE 2: Training time.

\begin{tabular}{lcccr}
\hline Model & SVR training time (s) & $R^{2}$ & Neural network training time $(\mathrm{s})$ & $R^{2}$ \\
\hline$P_{\text {fan }}$ & 21.41 & 0.9996 & Over 1800 & 0.9966 \\
$P_{\text {pump }}$ & 13.84 & 0.9998 & Over 1800 & 0.9999 \\
$P_{\text {chiller_up }}$ & 221.03 & 0.9976 & Over 1800 & 0.9981 \\
$P_{\text {chiller_down }}$ & 455.63 & 0.9997 & Over 1800 & 0.9997 \\
$Q_{\text {fan }}$ & 32.84 & 0.9999 & Over 1800 & 0.9965 \\
\hline
\end{tabular}

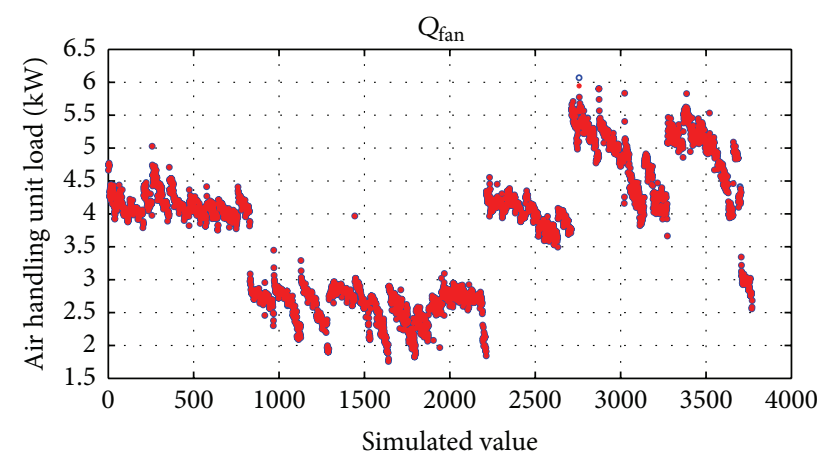

- Measurement data

- Regression data

FIGURE 11: Actual load and simulated load of air handling unit through SVR prediction.

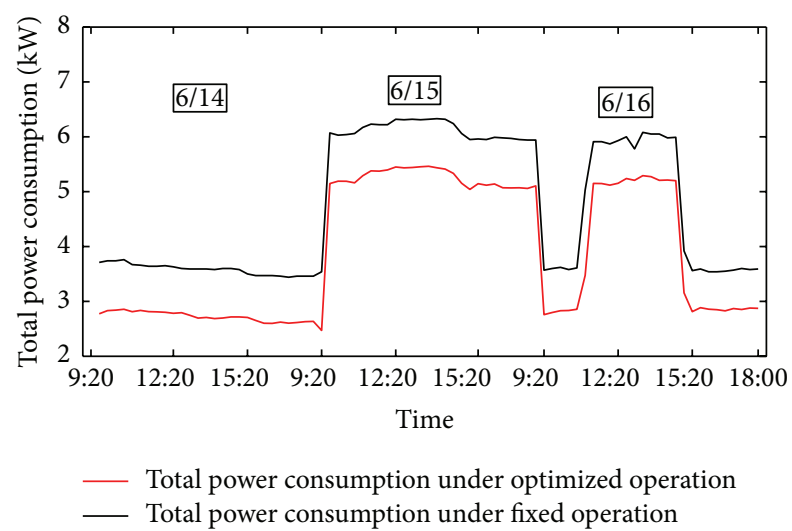

FIGURE 12: Curve diagram of total power consumption under fixed operation and optimized operation.

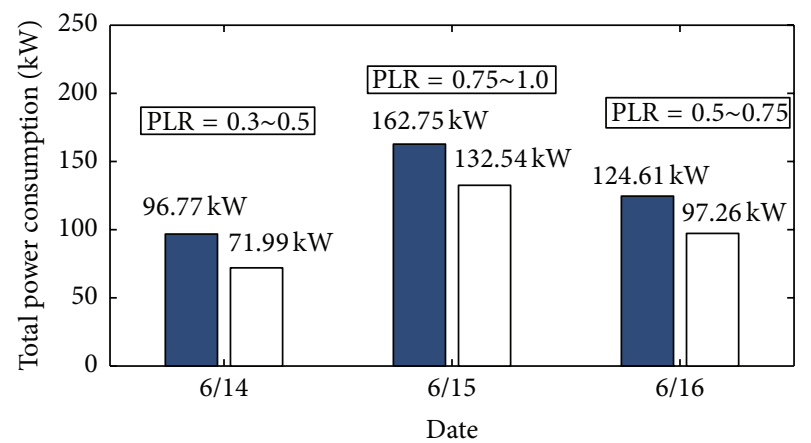

Total power consumption under fixed operation

Total power consumption under optimized operation

FIGURE 13: Bar chart of total power consumption before and after system improvement.
TABLE 3: Optimized operation parameters setting.

\begin{tabular}{|c|c|c|c|c|}
\hline Day & Time & $\begin{array}{c}T_{\text {chws }} \\
{ }^{\circ} \mathrm{C} \\
\end{array}$ & $\begin{array}{c}\dot{m}_{a} \\
\mathrm{CMH}\end{array}$ & $\begin{array}{l}\dot{m}_{\mathrm{chw}} \\
\mathrm{CMH}\end{array}$ \\
\hline $2009 / 6 / 14$ & 9:20 & 12.94 & 962.88 & 1.9 \\
\hline 2009/6/14 & 9:40 & 10.44 & 997.45 & 1.92 \\
\hline 2009/6/14 & $10: 00$ & 10.25 & 1031.7 & 1.9 \\
\hline $2009 / 6 / 14$ & $10: 20$ & 10.06 & 1040.1 & 2 \\
\hline 2009/6/14 & $10: 40$ & 10.5 & 1094.3 & 1.94 \\
\hline$\vdots$ & $\vdots$ & $\vdots$ & $\vdots$ & $\vdots$ \\
\hline 2009/6/14 & $16: 20$ & 10.89 & 958.79 & 1.89 \\
\hline 2009/6/14 & $16: 40$ & 12.98 & 1101.1 & 1.99 \\
\hline $2009 / 6 / 14$ & $17: 00$ & 13.12 & 1068 & 2.01 \\
\hline 2009/6/14 & $17: 20$ & 13.39 & 1124 & 2.04 \\
\hline 2009/6/14 & $17: 40$ & 13.22 & 1105.8 & 2.03 \\
\hline 2009/6/14 & $18: 00$ & 13.05 & 1079.9 & 2 \\
\hline $2009 / 6 / 15$ & 9:20 & 12.26 & 963.27 & 1.9 \\
\hline $2009 / 6 / 15$ & $9: 40$ & 6.6 & 1417.1 & 1.9 \\
\hline $2009 / 6 / 15$ & $10: 00$ & 7.87 & 1589.3 & 1.86 \\
\hline $2009 / 6 / 15$ & $10: 20$ & 6.75 & 1499.2 & 2.15 \\
\hline $2009 / 6 / 15$ & $10: 40$ & 6.7 & 1451.6 & 1.85 \\
\hline$\vdots$ & $\vdots$ & $\vdots$ & $\vdots$ & $\vdots$ \\
\hline $2009 / 6 / 15$ & $16: 20$ & 6.49 & 1071.7 & 2.72 \\
\hline $2009 / 6 / 15$ & $16: 40$ & 6.43 & 1332.7 & 2.08 \\
\hline $2009 / 6 / 15$ & $17: 00$ & 6.55 & 1346.5 & 2.09 \\
\hline 2009/6/15 & $17: 20$ & 7.49 & 1125.4 & 2.53 \\
\hline $2009 / 6 / 15$ & $17: 40$ & 7.24 & 1082.2 & 2.59 \\
\hline $2009 / 6 / 15$ & $18: 00$ & 7.13 & 1535.1 & 2.04 \\
\hline $2009 / 6 / 16$ & $9: 20$ & 10.4 & 1002.8 & 1.88 \\
\hline $2009 / 6 / 16$ & $9: 40$ & 10.98 & 992.85 & 1.97 \\
\hline $2009 / 6 / 16$ & $10: 00$ & 11.14 & 1142 & 1.85 \\
\hline $2009 / 6 / 16$ & $10: 20$ & 10.5 & 1115.3 & 2.01 \\
\hline $2009 / 6 / 16$ & $10: 40$ & 10.62 & 1048.3 & 1.99 \\
\hline$\vdots$ & $\vdots$ & $\vdots$ & $\vdots$ & $\vdots$ \\
\hline $2009 / 6 / 16$ & $16: 40$ & 10.53 & 1090.5 & 2 \\
\hline $2009 / 6 / 16$ & $17: 00$ & 10.61 & 1237.7 & 1.91 \\
\hline $2009 / 6 / 16$ & $17: 20$ & 10.62 & 1102.8 & 2.03 \\
\hline 2009/6/16 & $17: 40$ & 10.57 & 1229.5 & 2 \\
\hline $2009 / 6 / 16$ & $18: 00$ & 10.49 & 1199.4 & 2.01 \\
\hline $2009 / 6 / 16$ & $16: 40$ & 10.53 & 1090.5 & 2 \\
\hline
\end{tabular}

operated under the optimized model decrease energy consumption by $22 \%$ on average. 
It can therefore be confirmed that the SVM can accurately predict power consumption of various equipment and air handling unit loads. Additionally, genetic algorithm has powerful search capacity to find the best combination of operating parameters.

\section{Nomenclature}

$\mathrm{kW}_{\text {total }}$ : Total power consumption

$\dot{m}_{a_{n}}: \quad$ Air flow of air handling unit $i\left(\mathrm{~m}^{3} / \mathrm{hr}\right)$

$\dot{m}_{\text {chw }_{n}}$ : Chilled water flow of air handling unit $n$ $\left(\mathrm{m}^{3} / \mathrm{hr}\right)$

$P_{\text {chiller }_{i}}:$ The chiller power consumption $i(\mathrm{~kW})$

$P_{\mathrm{fan}_{n}}$ : The air handling unit power consumption $n(\mathrm{~kW})$

$P_{\text {pump }_{j}}:$ The pump power consumption $j(\mathrm{~kW})$

Q: $\quad$ Predicted cooling load of air handling unit (Ton)

$Q_{\text {real }}$ : Cooling load of air conditioning system provided to space (Ton)

$Q_{\text {chiller }_{i}}$ : Cooling capacity of chiller $i$ (Ton)

$T_{a_{n}}$ : Return air wet bulb temperature of air handling unit $\left({ }^{\circ} \mathrm{C}\right)$

$T_{\mathrm{chw}_{n}}$ : Inlet temperature of chilled water of air handling unit $n\left({ }^{\circ} \mathrm{C}\right)$

$T_{\mathrm{cwr}_{i}}$ : Inlet temperature of chilled water of chiller $i\left({ }^{\circ} \mathrm{C}\right)$

$T_{\mathrm{cws}_{i}}$ : Outlet temperature of chilled water of chiller $i\left({ }^{\circ} \mathrm{C}\right)$.

\section{Competing Interests}

The authors declare that they have no competing interests.

\section{References}

[1] J. Martin, "The crucial role of inverter drives in the energyefficient building," World Pumps, vol. 2006, no. 483, pp. 20-21, 2006.

[2] Z. Li and S. Deng, "A DDC-based capacity controller of a direct expansion (DX) air conditioning (A/C) unit for simultaneous indoor air temperature and humidity control-part I: control algorithms and preliminary controllability tests," International Journal of Refrigeration, vol. 30, no. 1, pp. 113-123, 2007.

[3] R. Saidur, "A review on electrical motors energy use and energy savings," Renewable and Sustainable Energy Reviews, vol. 14, no. 3, pp. 877-898, 2010.

[4] L. Lu, W. J. Cai, L. Xie, S. Li, and Y. C. Soh, "HVAC system optimization-in-building section," Energy and Buildings, vol. 37, no. 1, pp. 11-22, 2005.

[5] J. M. Link, P. M. Yager, and J. C. Anjos, "Application of genetic programming to high energy physics event selection," Nuclear Instruments and Methods in Physics Research A, vol. 551, no. 2-3, pp. 504-527, 2005.

[6] Y.-S. Lee and L.-I. Tong, "Forecasting energy consumption using a grey model improved by incorporating genetic programming," Energy Conversion and Management, vol. 52, no. 1, pp. 147-152, 2011.
[7] N. Togun and S. Baysec, "Genetic programming approach to predict torque and brake specific fuel consumption of a gasoline engine," Applied Energy, vol. 87, no. 11, pp. 3401-3408, 2010.

[8] M. Schwedler and B. Bradley, "Variable-primary-flow system," in Heading/Piping/Air Conditioning Engineer, pp. 41-44, 2000.

[9] J. E. Braun, S. A. Klein, J. W. Mitcell, and W. A. Beckman, "Applications of optimal control to chilled water systems without storage," ASHRAE Transactions, vol. 95, pp. 663-675, 1989.

[10] J. E. Braun, Methodologies for the design and control of central of cooling plants [Ph.D. thesis], University of Wisconsin, 1988.

[11] R. J. Hackner, J. W. Mitcell, and W. A. Beckman, "HVAC system dynamaics and energy use in buildings-part I," ASHRAE Transactions, vol. 90, pp. 523-535, 1984.

[12] L. Lu, W. Cai, Y. S. Chai, and L. Xie, "Global optimization for overall HVAC systems-part I, problem formulation and analysis," Energy Conversion and Management, vol. 46, no. 7-8, pp. 999-1014, 2005.

[13] S. S. Ding and D. Xianzhong, "Grey forecast model and its application," Journal of Harbin Institute of Technology (New Series), vol. 10, pp. 315-320, 2003.

[14] Y. Yao, Z. Lian, Z. Hou, and W. Liu, "An innovative airconditioning load forecasting model based on RBF neural network and combined residual error correction," International Journal of Refrigeration, vol. 29, no. 4, pp. 528-538, 2006.

[15] Y.-C. Chang, T.-S. Chan, and W.-S. Lee, "Economic dispatch of chiller plant by gradient method for saving energy," Applied Energy, vol. 87, no. 4, pp. 1096-1101, 2010.

[16] A. Beghi, L. Cecchinato, and M. Rampazzo, "A multi-phase genetic algorithm for the efficient management of multi-chiller systems," Energy Conversion and Management, vol. 52, no. 3, pp. 1650-1661, 2011.

[17] R. Z. Freire, G. H. C. Oliveira, and N. Mendes, "Development of regression equations for predicting energy and hygrothermal performance of buildings," Energy and Buildings, vol. 40, no. 5, pp. 810-820, 2008.

[18] X.-C. Xi, A.-N. Poo, and S.-K. Chou, "Support vector regression model predictive control on a HVAC plant," Control Engineering Practice, vol. 15, no. 8, pp. 897-908, 2007.

[19] A. E. Ben-Nakhi and M. A. Mahmoud, "Cooling load prediction for buildings using general regression neural networks," Energy Conversion and Management, vol. 45, no. 13-14, pp. 2127-2141, 2004.

[20] Y.-C. Chang and W.-H. Chen, "Optimal chilled water temperature calculation of multiple chiller systems using Hopfield neural network for saving energy," Energy, vol. 34, no. 4, pp. 448-456, 2009.

[21] Y.-W. Wang, W.-J. Cai, Y.-C. Soh, S.-J. Li, L. Lu, and L. Xie, "A simplified modeling of cooling coils for control and optimization of HVAC systems," Energy Conversion and Management, vol. 45, no. 18-19, pp. 2915-2930, 2004.

[22] Y.-C. Chang, "Genetic algorithm based optimal chiller loading for energy conservation," Applied Thermal Engineering, vol. 25, no. 17-18, pp. 2800-2815, 2005.

[23] M. He, W.-J. Cai, and S.-Y. Li, "Multiple fuzzy model-based temperature predictive control for HVAC systems," Information Sciences, vol. 169, no. 1-2, pp. 155-174, 2005.

[24] D. J. Swider, "A comparison of empirically based steady-state models for vapor-compression liquid chillers," Applied Thermal Engineering, vol. 23, no. 5, pp. 539-556, 2003.

[25] V. N. Vapnik, Statistical Learning Theory, John Wiley \& Sons, New York, NY, USA, 1998. 
[26] W. Y. Zhang, W.-C. Hong, Y. Dong, G. Tsai, J.-T. Sung, and G.F. Fan, "Application of SVR with chaotic GASA algorithm in cyclic electric load forecasting," Energy, vol. 45, no. 1, pp. 850858, 2012.

[27] T. Joachims, "Text categorization with support vector machines: learning with many relevant features," in Machine Learning: ECML-98, C. Nédellec and C. Rouveirol, Eds., vol. 1398 of Lecture Notes in Computer Science, pp. 137-142, Springer, Berlin, Germany, 1998.

[28] C. J. C. Burges, "A tutorial on support vector machines for pattern recognition," Data Mining and Knowledge Discovery, vol. 2, no. 2, pp. 121-167, 1998.

[29] N. Cristianini and J. Shawe-Taylor, An Introduction to Support Vector Machines and Other Kernel-Based Learning Methods, Cambridge University Press, Cambridge, UK, 2000.

[30] Z. Xu, Y. Gao, and Y. Jin, "Application of an optimized SVR model of machine learning," International Journal of Multimedia and Ubiquitous Engineering, vol. 9, no. 6, pp. 67-80, 2014.

[31] S. Ye, G. Zhu, and Z. Xiao, "Long term load forecasting and recommendations for china based on support vector regression," Energy and Power Engineering, vol. 4, no. 5, pp. 380-385, 2012.

[32] Y.-C. Chang, "Sequencing of chillers by estimating chiller power consumption using artificial neural networks," Building and Environment, vol. 42, no. 1, pp. 180-188, 2007.

[33] J. H. Holland, Adaptation in Natural and Artificial Systems: An Introductory Analysis with Applications to Biology, Control, and Artificial Intelligence, University of Michigan Press, Ann Arbor, Mich, USA, 1975.

[34] M. Melanie, An Introduction to Genetic Algorithms, A Bradford Book, The MIT Press, 1999. 


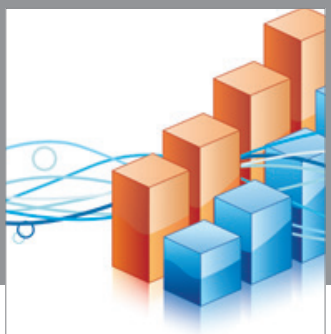

Advances in

Operations Research

vatem alat4

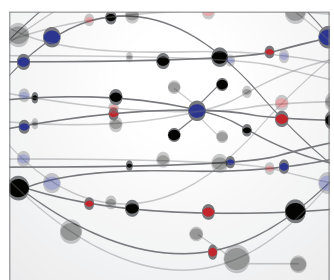

\section{The Scientific} World Journal
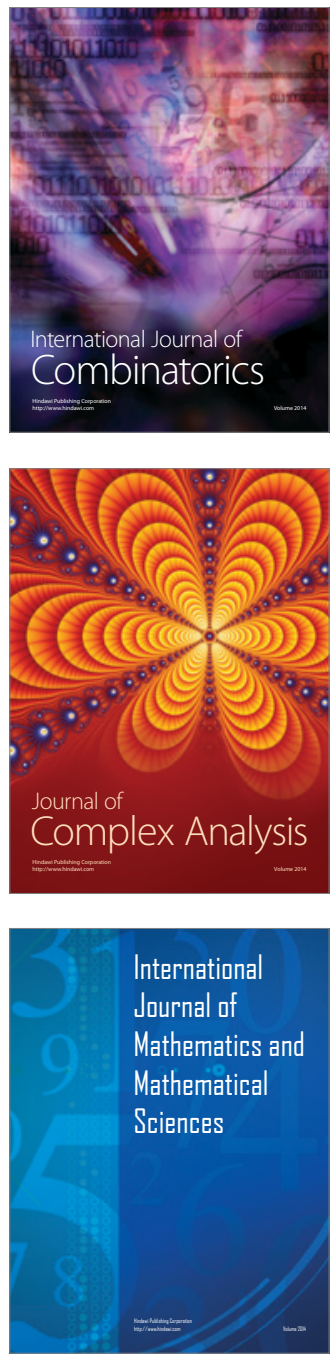
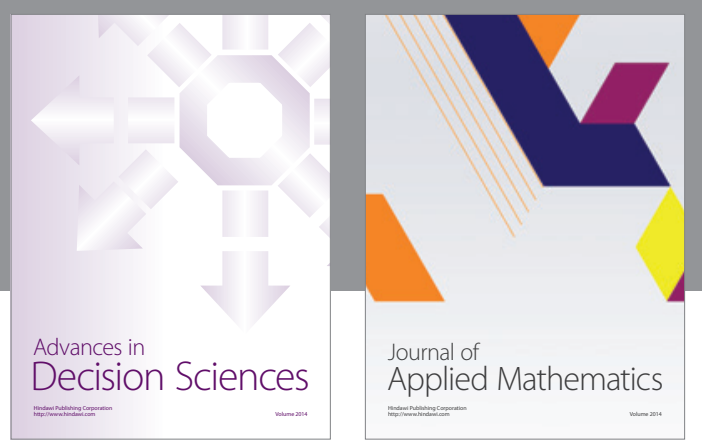

Algebra

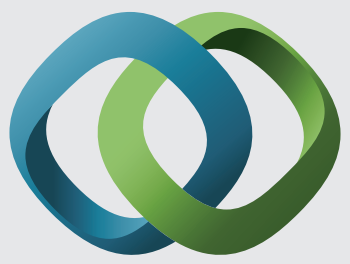

\section{Hindawi}

Submit your manuscripts at

http://www.hindawi.com
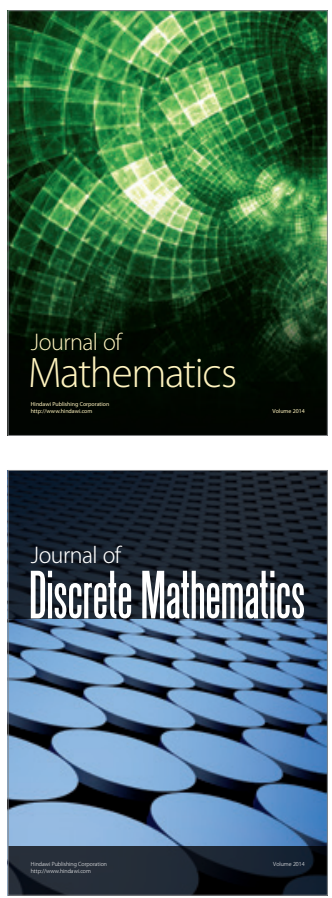

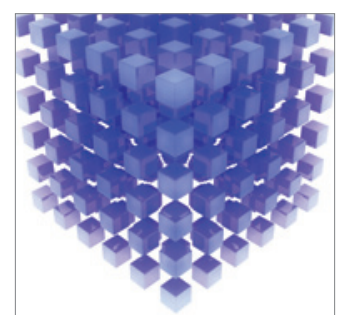

Mathematical Problems in Engineering
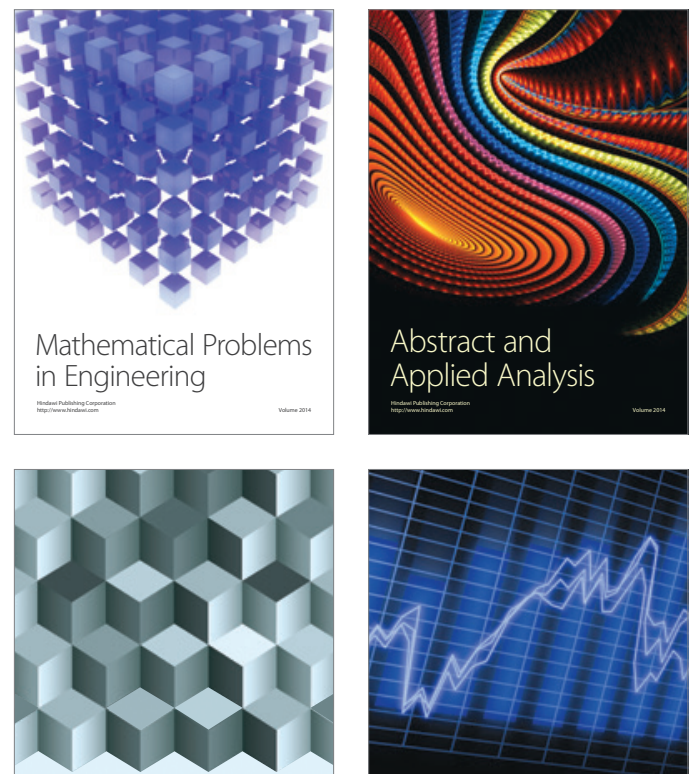

Journal of

Function Spaces

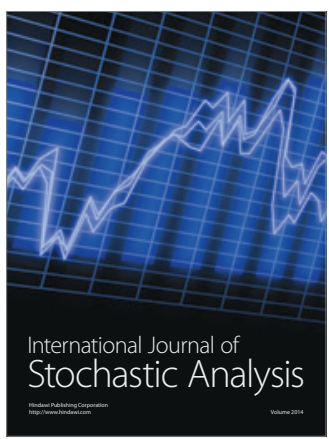

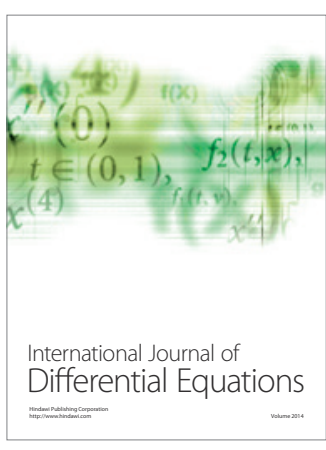
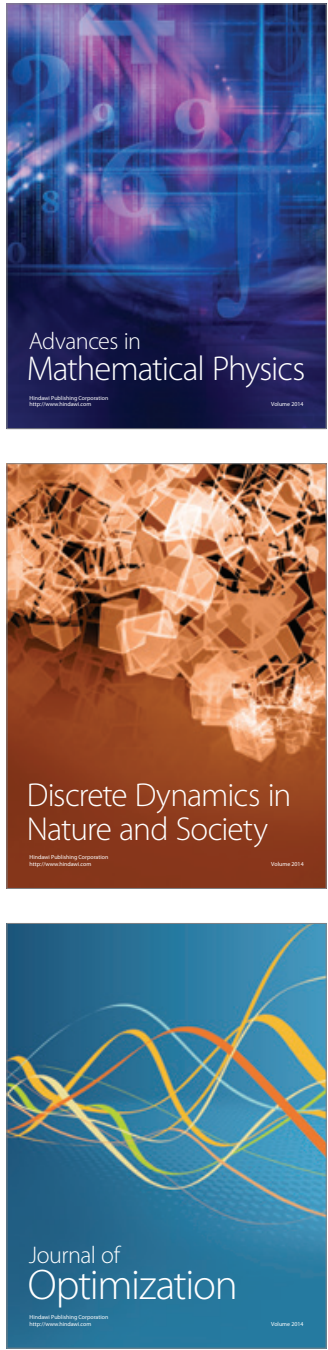